PAPER

\title{
Persistent neurocognitive impairments associated with severe falciparum malaria in Kenyan children
}

\author{
J A Carter, V Mung'ala-Odera, B G R Neville, G Murira, N Mturi, C Musumba, C R J C Newton
}

See Editorial Commentary, p 467

J Neurol Neurosurg Psychiatry 2005;76:476-481. doi: 10.1136/jnnp.2004.043893

See end of article for authors' affiliations

.....................

Correspondence to: $\operatorname{Dr} J$ A Carter, Centre for International Child Health, Institute of Child Health, 30 Guilford Street, London WCIN 1EH, UK; j.carter@ ich.ucl.ac.uk

Received 20 April 2004 In revised form 9 July 2004 Accepted 18 July 2004
Objectives: There is little information on the characteristics of persisting impairments associated with severe forms of falciparum malaria. Previous work has suggested the existence of a group of children with particularly poor performance on neurocognitive assessments in the context of average group performance. The aim of this study was to provide a detailed characterisation of impairments in this subgroup.

Methods: Three groups of children were recruited: children admitted up to nine years earlier with cerebral malaria $(C M)(n=152)$, malaria and complicated seizures $(M / S)(n=156)$, or those unexposed to either condition $(n=179)$. Each child underwent a series of developmental assessments. Standard definitions were used to classify impairment.

Results: Twenty four percent of the CM and M/S groups had at least one impairment in the major domains assessed in the study, compared with $10 \%$ of the unexposed group. CM was associated with a higher proportion of multiple impairments and an increased risk of mortality in the first year after recovery in those identified with impairments on discharge.

Conclusions: After severe malaria, some children have neurocognitive impairments that are evident as long as nine years later. Impairments may become more evident as children progress and face more complex cognitive and linguistic demands, socially and educationally. The child's neurological status at discharge was not a good predictor of later neurocognitive impairment. This highlights the importance of follow up for children with severe malaria and the involvement of therapists and educators in the provision of services for this population.
C erebral malaria (CM) is the most severe neurological presentation of acute falciparum malaria. The clinical hallmark is the presence of coma. ${ }^{1}$ Neurocognitive impairments associated with CM have been increasingly recognised over the past 20 years. ${ }^{2}$ However, the longterm effects of impairments are poorly characterised and their importance to the burden of malaria rarely discussed. The prevalence of neurocognitive impairments in the much larger group of children presenting with malaria and seizures without coma has received even less attention, and has only recently been described in any detail. ${ }^{3}$

The few longterm follow up studies of childhood survivors of CM have reported impairments in $3-31 \%$ of children, ${ }^{4-7}$ with a weighted mean of $10.9 \% .^{2}$ Only one report has offered a comprehensive analysis of longterm impairments associated with $\mathrm{CM}^{8}{ }^{8}$ but followed up a selected group of children $(n=452)$ for 18 months only. Their findings suggest that a broad range of developmental deficits may persist after recovery.

Methodological shortcomings limit the usefulness of previous studies. First, few studies have recruited a comparison group. This is particularly important in studies in resource poor countries, which often report a higher prevalence of impairments in the general population than in resource rich countries. For example, 7\% of 2-9 year old Bangladeshi children ${ }^{9}$ and $10.7 \%$ of $6-9$ year old children surveyed in rural Kenya were found to have neurological impairment. Second, there is no universally accepted system for defining impairment on non-standardised neurocognitive assessments ${ }^{10}$ : many previous studies have not stated the definition they have used, making cross study comparisons difficult.

We examined the longterm outcome in children with two different severe presentations of acute falciparum
malaria-CM and malaria with complicated seizures (M/ S)-comparing the results with those of a group unexposed to either condition. The study produced two types of outcome data: statistical differences between exposed and unexposed groups, providing evidence of the community impact of severe malaria, and specific clinical data, which help in understanding the pathogenic mechanisms. The results suggested the existence of a group of children with particularly poor performance in the context of average group performance: in this paper, we provide a more detailed characterisation of this group.

\section{METHODS}

Participants were recruited from a demarcated study area on the coast of Kenya. Children were between 6.0 and 9.11 years of age when they were assessed. All children exposed to CM, born between 1991 and 1995 and living in the study area, were identified from databases of admissions to Kilifi District Hospital (KDH). An equal number of children admitted with $\mathrm{M} / \mathrm{S}$ were identified from this database. A random sample of children unexposed to severe malaria was drawn from a census database of children living in the study area. All children spoke a Mijikenda language as their first language and fulfilled one of the following group criteria:

(1) Children who had been admitted to $\mathrm{KDH}$ with $\mathrm{CM}$ (defined as a Blantyre coma score ${ }^{11}$ of $\leqslant 2$ for four or more hours, a peripheral parasitaemia, and the exclusion

Abbreviations: $\mathrm{Cl}$, confidence interval; $\mathrm{CM}$, cerebral malaria; $I Q R$, interquartile range; $\mathrm{KDH}$, Kilifi District Hospital; $M / S$, malaria and complicated seizures; OR, odds ratio; RBMTC, Rivermead Behavioural Memory Test for Children; SES, socioeconomic status; WHO, World Health Organisation 
Table 1 Children diagnosed with low nutritional status

\begin{tabular}{lllll}
\hline & CM (\%) & M/S (\%) & Unexposed (\%) & Total (\%) \\
\hline Stunted & $36(24)$ & $28(19)$ & $25(14)$ & $89(19)$ \\
Wasted & $2(1)$ & $1(1)$ & $2(1)$ & $5(1)$ \\
Underweight & $19(13)$ & $16(11)$ & $13(7)$ & $48(10)$ \\
\hline \multicolumn{2}{l}{ CM, cerebral malaria; M/S, malaria and complicated seizures. }
\end{tabular}

of other causes of encephalopathy. This definition fulfils the World Health Organisation (WHO) criteria for $\mathrm{CM}^{12}$ ).

(2) Children who had been admitted to $\mathrm{KDH}$ with a primary diagnosis of M/S ( $>2$ seizures within 24 hours or focal or prolonged $>30$ minutes) but who did not develop coma (able to localise a painful stimulus within one hour of the seizure).

(3) Children who had not previously been admitted to $\mathrm{KDH}$ with either complication of severe falciparum malaria.

Children in groups 1 and 2 were treated with quinine and/ or chloroquine or pyrimethamine/sulfadoxine; none received mefloquine. Children were excluded if they refused verbal informed consent or if their parents refused written informed consent. Ethical permission for the study was obtained from the Kenyan national ethics committee and the Institute of Child Health, London, UK.

Each child underwent a battery of assessments: cognition, motor, speech and language, hearing, and vision. The cognitive assessment included tests of memory based on the Rivermead Behavioural Memory Test for Children (RBMTC), ${ }^{13}$ non-verbal functioning, attention, and a parental rating of behavioural problems. ${ }^{14}$ The behaviour questionnaire was based on items drawn from the Vineland Adaptive Behaviour Scales, ${ }^{15}$ the Behaviour Screening Questionnaire, ${ }^{16}$ and the Kenya Institute of Special Education Screening Schedule. There were seven speech and language assessments: comprehension, syntax/morphology, semantics, pragmatics, higher level language, phonology, and word finding. ${ }^{3}$ The motor skills assessment comprised an assessment of cranial nerve function, motor function, and minor neurological dysfunction. ${ }^{17}$ Hearing was tested with a Kamplex screening audiometer (PC Werth, London, UK) and vision, using a Sonksen-Silver chart. ${ }^{18}$

An obstetric/perinatal history was taken from each mother during our current study protocol. Developmental problems before the acute episode were determined from the child's hospital records, which included four questions on the child's developmental milestones (age appropriate ability to sit,

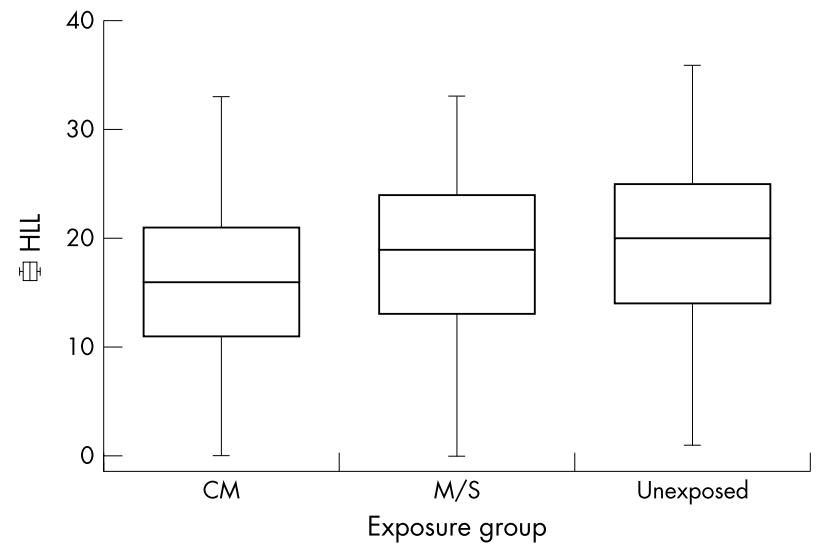

Figure 1 Distribution of higher level language (HLL) assessment scores by exposure group. $C M$, cerebral malaria; $M / S$, malaria and complicated seizures. stand, walk, and speak) recorded at admission. Standardised weight/height, height/age, and weight/age z scores were calculated as proxy measures for nutritional status using the NutStat program in EpiInfo 2000 (CDC, Atlanta, Georgia, USA). This uses reference data from the American National Centre for Health Statistics, which we used based on the premise of the equal growth potential of all children. ${ }^{19}$ Weight and height were measured using standardised scales by the two clinicians responsible for the motor skills examination. Data were collected on a series of indicators of socioeconomic status (SES). The mother's level of education was selected as a covariate for analysis, because it is often regarded as a predictor of child health and development in resource poor countries. ${ }^{20} 21$ The father's occupation was also selected, because it has been found to be associated with income level in previous studies on the Kenyan coast. ${ }^{22}$ Verbal necropsies were conducted with the parents of children reported to have died after discharge using the standard WHO method. ${ }^{23}$

All speech, language, and cognitive tests were based on standardised UK assessments, but were extensively altered in content and format to make them culturally appropriate. Reliability and validity testing supported their use in this context (JA Carter, PhD thesis, University of London, 2002). A team of assessors trained in the theoretical and practical aspects of assessment and fluent in the Mijikenda languages carried out the cognitive and speech and language assessments. The procedure will be described elsewhere. All assessors were blinded to the group status of each child.

The occurrence of particularly low scores was determined by comparing box plots of group scores for each assessment, where the box illustrates the interquartile range (IQR), and the central horizontal line, the mean or median. Very low scores, represented by circles, constitute data points more than 1.5 IQR beyond the first or third quartile. To determine levels of impairment, standard clinical classifications were used in the neurological, hearing, and vision assessments. None of the other assessments are standardised on the local population, so impairment was classified using a commonly

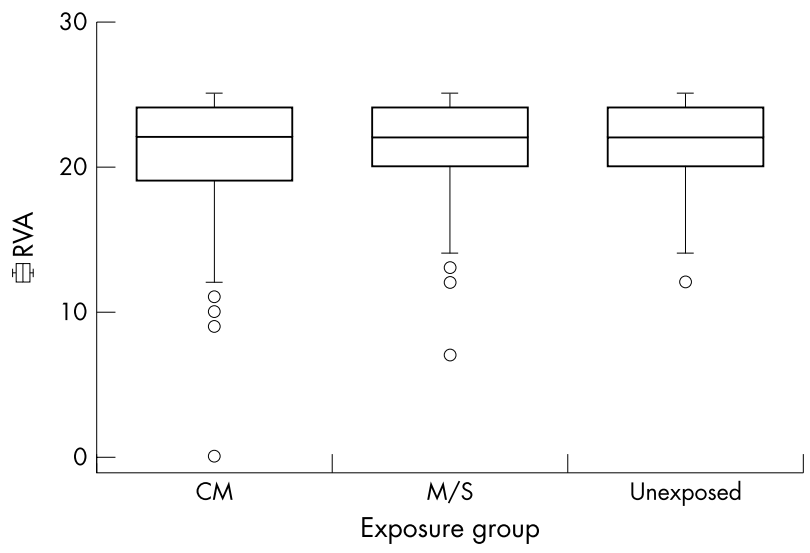

Figure 2 Distribution of receptive vocabulary assessment (RVA) scores by exposure group. CM, cerebral malaria; $M / S$, malaria and complicated seizures. 
accepted classification of ability levels. ${ }^{24}$ This was with the exception of the memory test, in which the scoring system followed that of the RBMTC, and the behaviour questionnaire, which had a scoring system piloted in a previous study. ${ }^{14}$ For the remaining assessments, an estimate of more than 2 SD below the age specific unexposed group mean or below the 2.0 centile of the unexposed group results was adopted for normally distributed and skewed data, respectively. A classification of "multiple impairments" described children with impaired performance in more than one developmental domain.

\section{RESULTS}

Two hundred and forty four children with a history of CM and 231 with a history of $\mathrm{M} / \mathrm{S}$ were identified from the $\mathrm{KDH}$ admissions databases. Two hundred and seventy three children unexposed to either condition were identified from the census database. Of these, 25 had subsequently died ( $14 \mathrm{CM}$; five $\mathrm{M} / \mathrm{S}$ ), 25 were found to be under/overage on age confirmation ( six CM; seven M/S), and 211 were no longer at the same address ( $72 \mathrm{CM} ; 63 \mathrm{M} / \mathrm{S}$ ). Thus, 487 children were recruited into the study, 152 children who had previously been hospitalised with CM, 156 with previous M/S, and 179 unexposed to either condition. Seventy seven $(51 \%)$ of the CM group, $72(46 \%)$ of the M/S group, and $93(52 \%)$ of the unexposed group were boys.

Few children attained $\mathrm{z}$ scores of more than " 0 " on the nutritional measures; the prevalence of stunting, wasting, and underweight was generally higher among children with a history of CM (table 1). However, multiple regression analyses, adjusted for age and sex, showed only one significant difference between the exposed and unexposed groups: children with previous $\mathrm{M} / \mathrm{S}$ had significantly higher

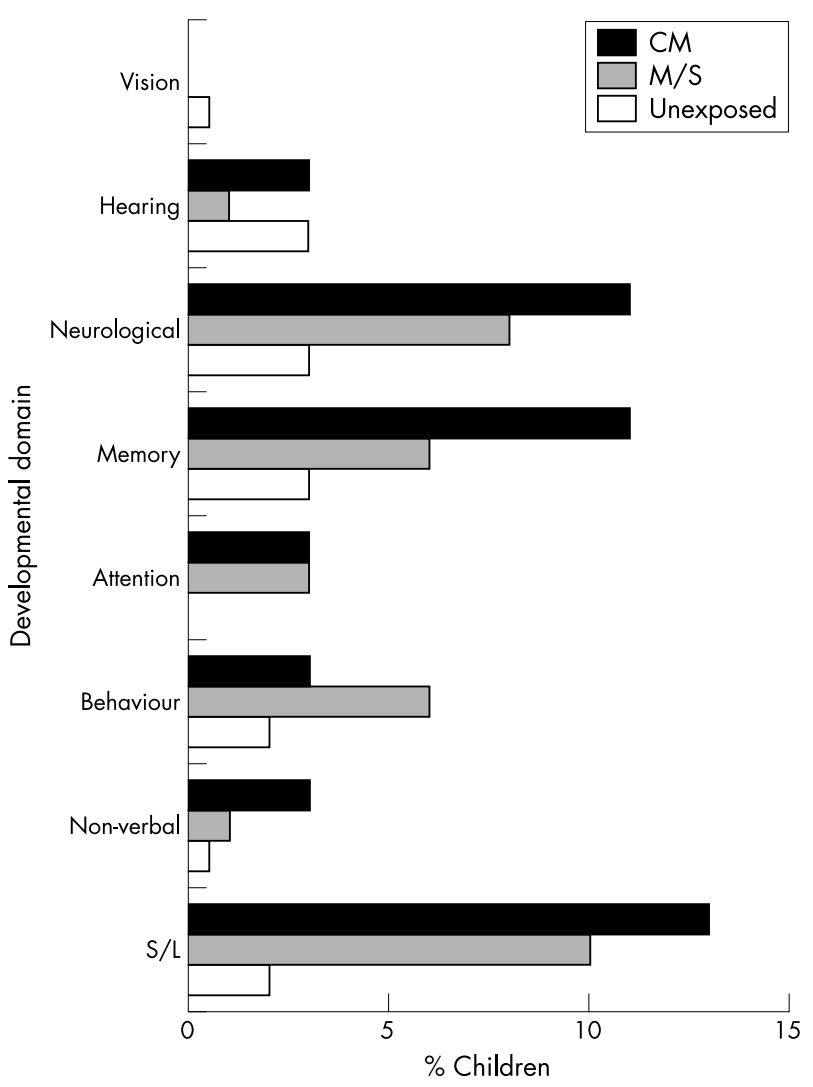

Figure 3 Proportion of children with impairments in each developmental domain, by exposure group. $C M$, cerebral malaria; $M / S$, malaria and complicated seizures; $S / L$, speech and language. weight/height $\mathrm{z}$ scores (estimated difference, 0.17; 95\% confidence interval (CI), 0.003 to $0.33 ; \mathrm{p}=0.05$ ) than children from the unexposed group.

The results of the SES questionnaire suggested a high degree of homogeneity between the exposed and unexposed groups. Over half of the mothers in our study had never attended school, in similar proportions in each group $\left(\chi^{2}=0.1 ; p=0.95\right)$. Those who had attended school were divided into two groups: those with lower primary level education (between 7 and 9 years of age) and those with any level higher than this. There was a significant difference in the proportions of mothers between each group $\left(\chi^{2}=7.28\right.$; $p=0.03)$, primarily as a result of the difference between the $\mathrm{CM}$ and $\mathrm{M} / \mathrm{S}$ groups. Almost half of the fathers were subsistence farmers. When the results were divided into two subgroups of subsistence farmers compared with income generating occupations (small business, professional or skilled employment, casual labourer), there was no evidence of a difference between the groups $\left(\chi^{2}=4.03 ; p=0.13\right)$.

Group results will be reported in detail elsewhere. Briefly, the group data displayed two typical distributions. First, some assessments had a downward distribution of scores in the exposed groups relative to the unexposed group, represented by lower mean/median and minimum scores (fig 1).

Typically, these assessments had no outliers and produced a significant difference in group scores between the exposed and unexposed groups. The second distribution was of similar mean/median scores, except for a trend towards lower minimum scores in the exposed groups (particularly the CM group), and the occurrence of very low scores in some children (fig 2). This scenario rarely produced a significant group difference but may indicate the existence of a group of children with particularly poor performance, in the context of average group performance.

Twenty four percent of the CM and M/S groups had at least one impairment in the major domains assessed in our study (motor skills, memory, behaviour, attention, non-verbal functioning, hearing, vision, speech, and language), compared with $10 \%$ of the unexposed group. Both CM (odds ratio (OR), 2.15; $95 \% \mathrm{CI}, 1.07$ to $4.3 ; \mathrm{p}=0.03$ ) and M/S (OR, 2.46; $95 \%$ CI, 1.24 to $4.9 ; \mathrm{p}=0.01$ ) were associated with significantly increased odds of an impairment level score. The speech and language battery was the most common locus of impairment in both groups exposed to severe malaria (fig 3). There were more impaired children in the CM group in each of the other domains except for behaviour, where there was a greatly increased number of $\mathrm{M} / \mathrm{S}$ group children with impairments compared with the other groups. Larger numbers of children with previous CM presented with more extensive impairments, as measured by the number of domains in which an impairment level score was assigned, than in the M/S or unexposed groups (fig 4). The proportion

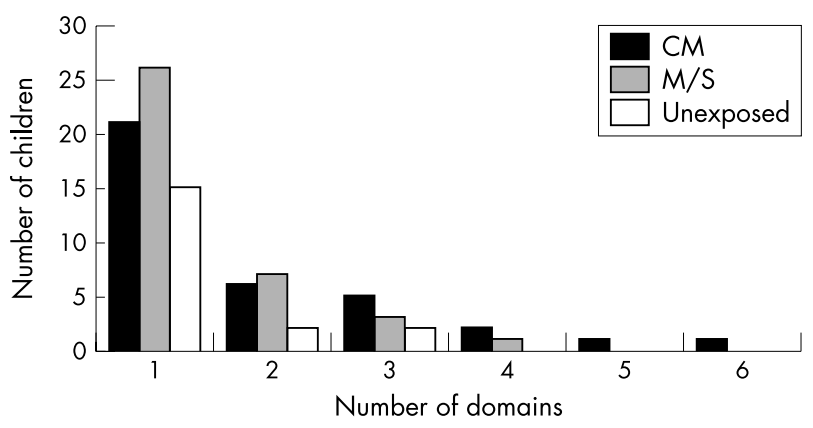

Figure 4 Number of domains with impairment level scores, by exposure group. $C M$, cerebral malaria; $M / S$, malaria and complicated seizures. 
of the CM impaired group with two or more impaired domains was $42 \%(\mathrm{n}=15)$ compared with $30 \%(\mathrm{n}=11)$ and $22 \%(\mathrm{n}=4)$ of the $\mathrm{M} / \mathrm{S}$ and unexposed impaired groups, respectively.

\section{Patterns of impairment}

Of the 15 children with multiple impairments in the CM group, six had a pattern of deficits that included impairments in the speech/language, memory, and motor skills domains and seven were impaired in speech and language and either memory or motor skills. A similar cluster was found in the M/ $S$ group: whereas only two children with multiple impairments presented with impairments in all three of these domains, five had impairments in any two.

Non-verbal functioning, behaviour, and attention were less often impaired relative to other domains in the CM and M/S groups. Impaired performance in these domains was associated with multiple impairments. Among the CM impaired group, nine were impaired in any one of these domains and seven of these children had impairments in at least three domains. Similarly, five of the M/S impaired group presented with impaired performance in non-verbal functioning or attention, all of whom were impaired in at least two domains. However, in contrast to the CM group, impaired behaviour was found as a single deficit in seven of those in the M/S group with impaired performance on the behaviour questionnaire.

Motor impairments were categorised according to a hierarchical classification of spasticity, ataxia, and fine motor dysfunction. Children diagnosed with "spasticity" also showed signs of ataxia (a broad term describing disturbance in control of posture and movement and not necessarily implying cerebellar dysfunction) and fine motor dysfunction, and children categorised as "ataxic" also displayed fine motor dysfunction. Spasticity was diagnosed in $17 \%(\mathrm{n}=6)$ of the CM impaired group, $8 \%(n=3)$ of the $M / S$ impaired group, and $6 \%(\mathrm{n}=1)$ of the unexposed impaired group. Ataxia was more common, being present in $25 \%(\mathrm{n}=9)$ of the CM impaired group, $22 \%(n=8)$ of the $M / S$ impaired group, and $17 \%(\mathrm{n}=3)$ of the unexposed group.

Impairments in special senses occurred rarely in either exposed group, even in children with multiple impairments.

\section{Low functioning group}

A subgroup of eight children was unable to attempt certain assessments because they were functioning at such a low level. Notes made by the assessors indicate that the reasons for non-completion were lack of understanding of the task demands, poor attention skills, and limited expressive language, in three children limited to single words.

Six of the eight children in this subgroup were from the CM group and two were from the M/S group (table 2), representing $3.9 \%$ and $1.3 \%$ of the $\mathrm{CM}$ and $\mathrm{M} / \mathrm{S}$ groups, respectively. All of the children were girls (Fisher's exact test, $p=0.007$ ) and all but one were in the younger age groups. None attended school. One child was reported to have a possible birth injury and had delayed speech and language development at the time of admission to hospital for CM, which may account for the impairments detected in our study. Three of the children, including both children from the $\mathrm{M} / \mathrm{S}$ group, had active epilepsy, defined as two or more seizures (not related to fever in those aged six years), with at least one seizure in the previous 12 months.

On the assessments these children were able to complete, all children had impairments on at least four of the speech and language assessments (table 1). Seven of the eight children were described as impaired on the memory test and the neurological (motor) examination. Motor impairments were classified as spasticity in two children (one M/S), ataxia in three children, and fine motor in two children (one M/S). Two children were assigned an impairment score on the behaviour questionnaire.

\section{Impairments on hospital discharge}

A neurological assessment was carried out on $51 \%(n=157$; $80 \%$ of the CM group and $22 \%$ of the M/S group) of the children from the exposed groups at the time of discharge from hospital. The occurrence of the assessment depended on the clinical protocol used during the year of discharge and the ward the child had been admitted to (children with CM were more likely to be admitted to the high dependency unit, where neurological discharge assessments were used), rather than any child or clinician characteristics. Physicians carried out a clinical assessment at discharge using a standard proforma.

Seventeen per cent $(n=21)$ of those from the CM group who underwent assessment had at least one impairment on discharge, as did $20 \%(n=7)$ of the M/S group. Motor impairments were the most prevalent, although this may reflect the method of assessment adopted. Thirty eight per cent of children identified with impairments on discharge after CM and 29\% after M/S exhibited impairment level scores on one or more assessments in our current study (table 3 ).

\section{Mortality after discharge}

Children admitted to hospital with CM had increased odds of death compared with those from the unexposed group (OR, 2.75; $95 \% \mathrm{CI}, 1.03$ to $7.33 ; \mathrm{p}=0.03$ ). Children identified as having neurological impairments on hospital discharge were more likely to die than those with no neurological impairments (OR, 10.5; 95\% CI, 2.86 to 39.79; p < 0.001).

In children exposed to $\mathrm{CM}$, the median time to death was 24 months (IQR, 5-36 months), with $29 \%$ of the deaths occurring within the first 12 months after discharge from hospital. The median age at death in the CM group was 32

Table 2 Demographic, developmental, and performance characteristics of the low functioning group

\begin{tabular}{|c|c|c|c|c|c|c|c|c|}
\hline & \multicolumn{8}{|c|}{ Identity number used in the study } \\
\hline & 034 & 184 & 285 & 415 & 451 & 471 & 253 & 428 \\
\hline $\begin{array}{l}\text { Diagnosis } \\
\text { Age (years) } \\
\text { Age of insult (years, months) } \\
\text { Prenatal or perinatal problems } \\
\text { Developmental problems premalaria } \\
\text { Epilepsy } \\
\text { Impairments on study assessments }\end{array}$ & $\begin{array}{l}\text { CM } \\
9 \\
2,10 \\
\text { No } \\
\text { No } \\
\text { Yes† } \\
\text { S/L (5)‡, } \\
M, N\end{array}$ & $\begin{array}{l}\text { CM } \\
7 \\
2,2 \\
\text { No } \\
\text { No } \\
\text { No } \\
\text { S/L (4), } \\
M, B, N\end{array}$ & $\begin{array}{l}\text { CM } \\
7 \\
2,7 \\
\text { No } \\
\text { No } \\
\text { No } \\
\text { S/L (5), } \\
M, B\end{array}$ & $\begin{array}{l}\text { CM } \\
7 \\
2,3 \\
\text { No } \\
\text { No } \\
\text { No } \\
\text { S/L (4), } \\
N\end{array}$ & $\begin{array}{l}\text { CM } \\
6 \\
3,1 \\
Y_{e s}^{*} \\
\text { Yes* } \\
\text { No } \\
\text { S/L (4), } \\
M, N\end{array}$ & $\begin{array}{l}\text { CM } \\
6 \\
3,3 \\
\text { No } \\
\text { No } \\
\text { No } \\
\text { S/L (7), } \\
M, N\end{array}$ & $\begin{array}{l}M / S \\
7 \\
3,0 \\
\text { No } \\
\text { No record } \\
\text { Yest } \\
S / L(4) \text {, } \\
M, N\end{array}$ & $\begin{array}{l}M / S \\
6 \\
2,1 \\
\text { No } \\
\text { No record } \\
\text { Yest } \\
\text { S/L (5) } \\
M, N\end{array}$ \\
\hline
\end{tabular}

*Problems breathing after birth; admitted to hospital for one week. Mother reported speech was delayed at the time of hospital admission. $†$ Patients with active epilepsy. $\ddagger$ The number in brackets indicates the number of speech and language assessments in which an impairment was detected $B$, behaviour; CM, cerebral malaria; $M$, memory; $M / S$, malaria and complicated seizures; $N$, neurological; $S / L$ speech/language. 
Table 3 Impairments detected on discharge and in the current study

\begin{tabular}{llll}
\hline ID & Group & Impairments detected at discharge & Impairments detected in current study \\
\hline 023 & $C M$ & Cortical blindness, right hemiplegia & $\mathrm{S} / \mathrm{L}$, non-verbal, behaviour, memory, attention, neurological \\
037 & $\mathrm{CM}$ & Unspecified & Memory \\
054 & $\mathrm{CM}$ & Cannot walk unsupported & $\mathrm{S} / \mathrm{L}$, memory \\
285 & $\mathrm{CM}$ & Unspecified & $\mathrm{S} / \mathrm{L}$, behaviour, memory (low functioning group) \\
333 & $\mathrm{CM}$ & Unsteady & Non-verbal, memory, attention, inactive epilepsy \\
408 & $\mathrm{CM}$ & Left hemiplegia & Neurological \\
455 & $\mathrm{CM}$ & Cannot sit & Hearing \\
487 & $\mathrm{CM}$ & Epilepsy & $\mathrm{S} / \mathrm{L}$, neurological, active epilepsy \\
118 & $\mathrm{M} / \mathrm{S}$ & Unspecified & $\mathrm{S} / \mathrm{L}$ \\
421 & $\mathrm{M} / \mathrm{S}$ & Cannot stand & Attention, neurological \\
\hline
\end{tabular}

$C M$, cerebral malaria; ID, identity number used in this study; $M / S$, malaria and complicated seizures; $S / L$ speech/language.

months (IQR, 28-80 months). Verbal necropsies conducted after a median of 68 months (IQR, 18-77) after death indicated that most children died from syndromes of malaria or meningitis, or from acute respiratory tract infections.

\section{DISCUSSION}

Twenty four percent of children exposed to severe malaria had an impairment level score in one or more of the major domains assessed in our study, compared with $10 \%$ of the unexposed group. Children exposed to $\mathrm{CM}$ had a more extensive pattern of impairments, with $42 \%$ of those with impairments having multiple impairments, compared with $30 \%$ of the $\mathrm{M} / \mathrm{S}$ and $22 \%$ of the unexposed groups. Impairments occurred in the exposed groups in all of the domains tested, apart from vision, suggesting that severe falciparum malaria may affect multiple aspects of development in children, or that a general depression of performance ability in some children meant that they were unable to complete many assessments successfully.

Speech and language was the most common locus of impairment in both exposed groups. This suggests that language impairment may be part of a generalised impairment that is more conspicuous in the language domain. Alternatively, the prevalence of language deficits may simply reflect the fact that this domain was subject to more detailed assessment than some others-for example, cognition, in which assessments were targeted towards specific skills-or may be a function of greater sensitivity of some measures. Motor and memory impairments were also common in both groups, affecting more than $10 \%$ of the CM group and up to $8 \%$ of the $\mathrm{M} / \mathrm{S}$ group. This suggests a pattern whereby impaired cognitive (including language, which may be the root cause of impairments on verbal components of other cognitive assessments) and motor performance is particularly associated with severe malaria. This corresponds to the results of a recent review of impairments associated with central nervous system infections, which reported that these domains were most commonly affected after infections such as meningitis and encephalitis. ${ }^{25}$

The proportion of impairments in the $\mathrm{CM}$ and $\mathrm{M} / \mathrm{S}$ groups was the same, suggesting that the number of children performing at the lower end of the spectrum is similar. However, the increased proportion of children with previous $\mathrm{CM}$ with multiple impairments indicates a pattern of more extensive impairments in the CM group. Levine ${ }^{26}$ comments that impairments in neurodevelopmental functions manifest differently depending on the pattern of weaknesses in other areas. Thus, although the proportion of children with impairments was the same in the CM and M/S groups, the $\mathrm{M} / \mathrm{S}$ group is probably more able to compensate for deficits in the absence of extensive concomitant impairments in most children.

The only previous study to have investigated persisting deficits across the spectrum of developmental domains found that $4.4 \%$ of survivors still had impairments after six months. ${ }^{8}$ Despite the apparent difference between these results and our current findings, a level of congruence is suggested by the fact that van Hensbroek and colleagues ${ }^{8}$ used a neurological examination to detect impairments and were thus likely to identify only gross deficits. In our current study, the group of children described as the "low functioning group", who represented $3.9 \%$ of the CM group, may be comparable to this group.

The eight children in the low functioning group were unable to complete many of the assessments and displayed limited ability to engage with the assessors at any level. Their level of performance suggests that these children would have difficulties in an educational environment without specific support, which is rarely available in rural Africa. None was attending school, although the reasons for this were not investigated. Stigma and reduced opportunities in education, marriage, and employment have been described for children with impairments. ${ }^{27}$ The negative consequences of impairments may also extend to the child's family, who rely on each family member for help in the home: for example, in most African homes, girls cook, clean the house, and look after younger siblings as early as 7 to 8 years of age.

Although high, the proportion of children with impairments in the unexposed group is comparable to levels found in other resource poor countries. ${ }^{9}$ The comparatively high level of impairments found in the unexposed group may have moderated the odds of impairment associated with CM or $\mathrm{M} / \mathrm{S}$, possibly underestimating the true impact of malaria on development. However, the effect of malaria cannot be separated from the impact of other detrimental factors in the sub-Saharan context if an accurate picture of child development and the factors influencing it is to emerge and influence clinical and educational practice. There is a complex interaction between factors associated with economically deprived conditions, and the examination of single determinants in isolation does not adequately reflect the multifactorial manner in which human development is determined. ${ }^{28}$ We tested for several confounding factors in our current study. There were few differences between the exposure groups in SES, indicating that the cohort was generally homogeneous in nature. The nutritional level of the cohort indicates that a large proportion of the group has experienced chronic inadequacies in nutrition and/or health, but with little disparity between the exposure groups. Studies conducted in this area have indicated that the prevalence of anaemia in the Kilifi community is similar to that of children admitted to hospital with malaria. ${ }^{29}{ }^{30}$ The potential impact of iron deficiency anaemia on development would thus be expected to be similar across the exposure groups, so this factor was not examined.

Our study confirms that the detection of neurological impairments on hospital discharge does not always predict 
persistent impaired performance, as measured by neurocognitive assessments. ${ }^{3}{ }^{14}$ These findings may indicate that the current assessment battery is more sensitive to brain damage associated with severe malaria than the screening assessment performed on hospital discharge. Alternatively, the concept of a continuum of deficits within each group is proposed, with a minority of children having moderate to severe impairments, some of whom die in the first year of discharge, and a large proportion of children having mild or subtle impairments. These milder impairments may have a minor effect on performance at a young age, but may become increasingly apparent with the child's advancing age, as the cognitive requirements of tasks increase in complexity.

Therefore, it is clear that severe malaria in which there is an acute encephalopathy, either satisfying the criteria for cerebral malaria or with complicated seizures in the acute phase, can be associated with persistent neurocognitive deficits. This may be one of the most common paediatric causes of impairment worldwide. Future studies with magnetic resonance imaging at both the acute phase and later will allow the delineation of specific aspects of pathogenesis.

Studies of other central nervous system infections suggest that deficits that have persisted for up to nine years are unlikely to improve and may even appear to worsen as children progress and face more complex cognitive and linguistic demands, socially and educationally. ${ }^{31}$ The low functioning group of children with severe impairments represents an even greater challenge in terms of appropriate educational and social provision, particularly in areas with few resources. Finally, the lack of congruence between those discharged with impairments and those with persisting impairments highlights the importance of follow up for children with severe malaria and the involvement of professional or community level rehabilitation workers and educators in the provision of services for this population.

\section{ACKNOWLEDGEMENTS}

We thank Mr J Gona, Ms L Obiero, Mr K Katana, Mr K Rimba, Ms J Tumaini, and Mr F Yaah for carrying out assessments; Mr D Konde for fieldwork; and Ms R Odhiambo for data entry. JA Carter (059336) and CRJC Newton (050533) are supported by The Wellcome Trust, UK. This paper is published with the permission of the director of KEMRI.

\section{Authors' affiliations}

J A Carter, B G R Neville, C R J C Newton, Neurosciences Unit, Institute of Child Health, The Wolfson Centre, Mecklenburgh Square, London WCIN 2AP, UK

J A Carter, V Mung'ala-Odera, G Murira, N Mturi, C Musumba, C R J C Newton, The Centre for Geographic Medicine Research (Coast), Kenya Medical Research Institute, PO Box 230, Kilifi, Kenya

Competing interests: none declared

\section{REFERENCES}

1 Newton CR, Hien TT, White N. Cerebral malaria. J Neurol Neurosurg Psychiatry 2000;69:433-41.

2 Newton CR, Krishna S. Severe falciparum malaria in children: current understanding of pathophysiology and supportive treatment. Pharmacol Ther 1998;79:1-53.

3 Carter JA, Murira GM, Ross A, et al. Speech and language sequelae of severe malaria in Kenyan children. Brain Inj 2003;17:217-24.
4 Bondi FS. The incidence and outcome of neurological abnormalities in childhood cerebral malaria: a long-term follow-up of 62 survivors. Trans $R$ Soc Trop Med Hyg 1992;86:17-19.

5 Brewster DR, Kwiatkowski D, White NJ. Neurological sequelae of cerebral malaria in children. Lancet 1990;336:1039-43.

6 Carme B, Bouquety JC, Plassart H. Mortality and sequelae due to cerebral malaria in African children in Brazzaville, Congo. Am J Trop Med Hyg 1993:48:216-21.

7 Meremikwu MM, Asindi AA, Ezedinachi E. The pattern of neurological sequelae of childhood cerebral malaria among survivors in Calabar, Nigeria. Cent Afr J Med 1997;43:231-4.

8 van Hensbroek MB, Palmer A, Jaffar S, et al. Residual neurologic sequelae after childhood cerebral malaria. J Pediatr 1997;131:125-9.

9 Khan N, Durkin M. Framework: prevalence. In: Zinkin P, McConachie H, eds. Disabled children and developing countries. London: MacKeith Press, 1995: 1-9.

10 Anderson SJ. On the importance of collecting local neuropsychological normative data. S Afr J Psychol 2001;31:29-34

11 Molyneux ME, Taylor TE, Wirima JJ, et al. Clinical features and prognostic indicators in paediatric cerebral malaria: a study of 131 comatose Malawian children. Q J Med 1989:71:441-59.

12 WHO Communicable Diseases Cluster. Severe falciparum malaria. Trans R Soc Trop Med Hyg 2000;94(suppl 1):S1-90.

13 Wilson B, Ivani-Chalian R, Aldrich F. The Rivermead behavioural memory test for children, 2nd ed. Bury St Edmunds, UK: Thames Valley Test Company, 1991.

14 Holding PA, Stevenson J, Peshu N, et al. Cognitive sequelae of severe malaria with impaired consciousness. Trans R Soc Trop Med Hyg 1999;93:529-34.

15 Sparrow SS, Balla DA, Cicchetti DV. Vineland adaptive behavior scales. Circle Pines, MN: American Guidance Service, 1984.

16 Richman N, Stevenson J, Graham PJ. Pre-school to school: a behavioural study. London: Academic Press, 1982.

17 Palisano R, Rosenbaum P, Walter S, et al. Development and reliability of a system to classify gross motor function in children with cerebral palsy. Dev Med Child Neurol 1997;39:214-23.

18 Salt AT, Sonksen PM, Wade A, et al. The maturation of linear acuity and compliance with the Sonksen-Silver Acuity System in young children. Dev Med Child Neurol 1995;37:505-14.

19 Richter L, Griesel R. Malnutrition, low birth weight and related influences on psychological development. In: Dawes A, Donald D, eds. Childhood and adversity. Perspectives from South African research. Claremont, SA: David Philip, 1994:66-91.

20 Coreil J. Health behavior in developing countries. In: Gochman DS, ed. Handbook of health behavior research III: demography, development and diversity. New York: Plenum Press, 1997:179-98.

21 Kvalsvig J, Connolly K. Health and psychological development among children in poor communities. In: Dawes A, Donald D, eds. Childhood and adversity. Psychological perspectives from South African research. Claremont, SA: David Philip, 1994:92-106.

22 Hoorweg J, Foeken D, Klaver W. Seasons and nutrition at the Kenya coast. Leiden: African Studies Centre, 1995.

23 WHO. A standard verbal autopsy method for investigating causes of death in infants and children. Geneva: World Health Organisation, 1999.

24 Lezak MD. Neuropsychological assessment, 3rd ed. New York: Oxford University Press, 1995

25 Carter JA, Neville BGR, Newton CRJC. Neuro-cognitive impairment following acquired central nervous system infections in childhood: a systematic review. Brain Res Rev 2003:43:57-69.

26 Levine MD. Neurodevelopmental variation and dysfunction among schoolaged children. In: Levine MD, Carey WB, Crocker AC, eds. Developmentalbehavioural pediatrics, 3rd ed. Philadelphia: WB Saunders Co, 1999:520-35.

27 Kisanii J. Growing up disabled. In: Zinkin P, McConachie H, eds. Disabled children and developing countries. London: MacKeith Press, 1995.

28 Wachs TD, McCabe G. The role of the environment in human nutritional research and intervention. In: Nutrition, health and child development. Research advances and policy recommendations. A joint publication: PAHO, The World Bank and the Tropical Metabolism Research Unit of the University of the West Indies: Washington DC: PAHO, 1998:14-31

29 Brooker S, Peshu N, Warn PA, et al. The epidemiology of hookworm infection and its contribution to anaemia among pre-school children on the Kenyan coast. Trans R Soc Trop Med Hyg 1999;93:240-6.

30 Newton CR, Warn PA, Winstanley PA, et al. Severe anaemia in children living in a malaria endemic area of Kenya. Trop Med Int Health 1997; 2:165-78.

31 Cross JA, Ozanne AE. Acquired childhood aphasia: assessment and treatment. In: Murdoch BE, eds. Acquired neurological speech and language disorders in childhood. London: Taylor and Francis, 1990:66-123. 